DANMARKS GEOLOGISKE UNDERS $\varnothing$ GELSE • DGU SERIE C • NR. 11 MILJØMINISTERIET • Geological Survey of Denmark · DGU SERIES C • NO. 11

\title{
Fibre length \\ by electronic \\ image analysis
}

вx

TORSTEN HOELSTAD

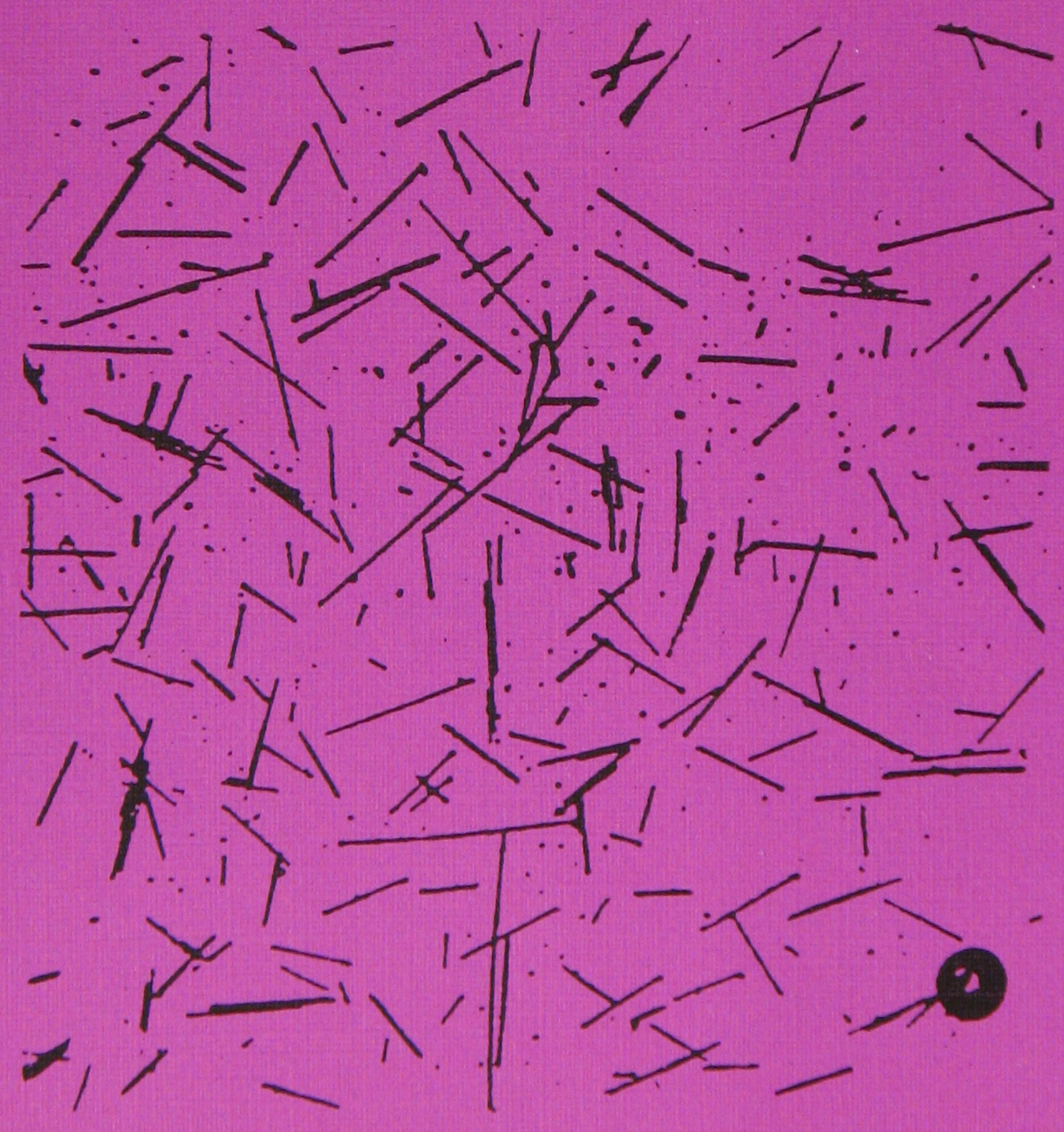

Danmarks Geologiske Undersøgelse · København 1993 


\section{Fibre length by electronic image analysis}

BY

TORSTEN HOELSTAD

Danmarks Geologiske Undersøgelse · København 1993 
Keywords: FibreLength, Image Analysis, Glass Fibres

Vignet: Example of Apperance of Glass Fibres in a Typical Preparation.

\section{DGU series $C$ no. 11}

ISBN 87-88640-96-5

ISSN $0900-6362$

Editor: Peter Frykman

Print: From og Co. and DGU

Printed in: 750 copies.

Date: 1. december 1992.

Torsten Hoelstad

Ministry of the Environment, Geological Survey of Denmark

Thoravej 8, DK-2400 Copenhagen NV

Telephone: +4531106600

Telefax:: + 4531196868 


\section{CONTENTS}

PREFACE $\ldots \ldots \ldots \ldots \ldots \ldots \ldots \ldots \ldots \ldots \ldots \ldots \ldots \ldots$

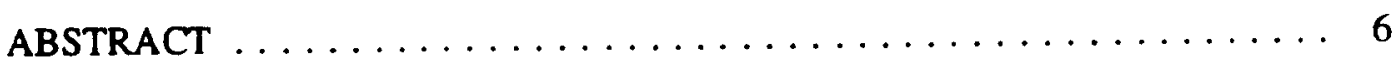

INTRODUCTION $\ldots \ldots \ldots \ldots \ldots \ldots \ldots \ldots \ldots \ldots \ldots$

MATERIAL, PREPARATION AND OPTICAL SETUP $\ldots \ldots \ldots \ldots \ldots \ldots$

ELECTRONIC IMAGE ANALYSIS $\ldots \ldots \ldots \ldots \ldots \ldots \ldots$ 9

CONSIDERATIONS ON THE DESIGN

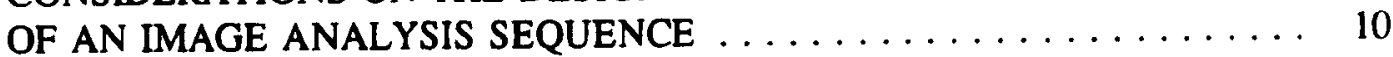

THE IMAGE ANALYSIS SEQUENCE $\ldots \ldots \ldots \ldots \ldots \ldots \ldots \ldots \ldots \ldots$

Shade correction reference image $\ldots \ldots \ldots \ldots \ldots \ldots \ldots \ldots \ldots$

Measuring frame extension $\ldots \ldots \ldots \ldots \ldots \ldots \ldots \ldots \ldots \ldots$

Clearing of image memories $\ldots \ldots \ldots \ldots \ldots \ldots \ldots \ldots \ldots \ldots$

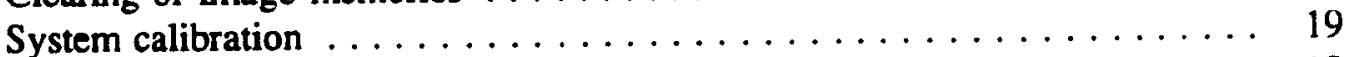

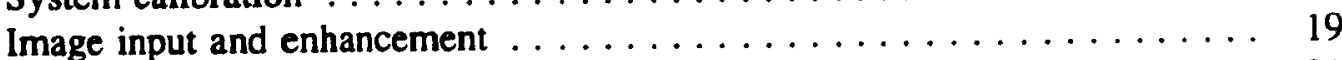

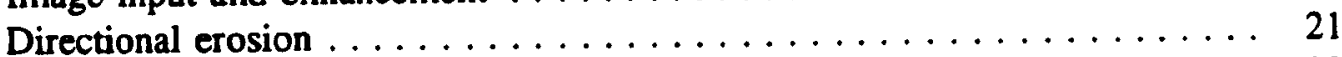

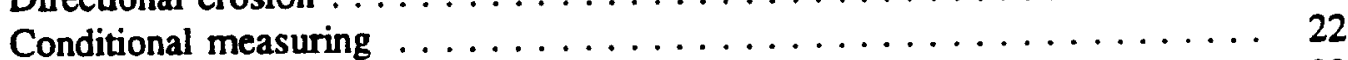

Length measurement and data storage $\ldots \ldots \ldots \ldots \ldots \ldots \ldots \ldots \ldots \ldots$

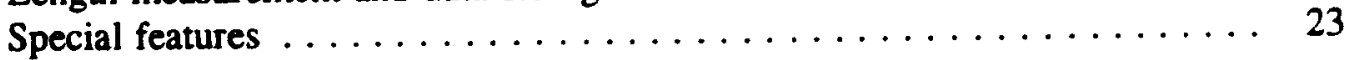

MEASURING PROCEDURE $\ldots \ldots \ldots \ldots \ldots \ldots \ldots \ldots \ldots \ldots \ldots$

PARAMETER THRESHOLDS $\ldots \ldots \ldots \ldots \ldots \ldots \ldots \ldots \ldots \ldots$

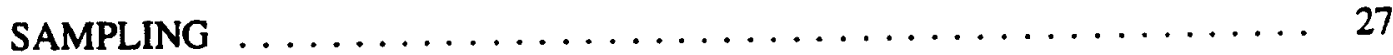

FIBRE AND PREPARATION REQUIREMENTS . . . . . . . . . . 27

SOURCES OF ERROR $\ldots \ldots \ldots \ldots \ldots \ldots \ldots \ldots \ldots \ldots \ldots$

CONCLUSIONS ........................... 29

ACKNOWLEDGEMENTS $\ldots \ldots \ldots \ldots \ldots \ldots \ldots \ldots \ldots \ldots \ldots$

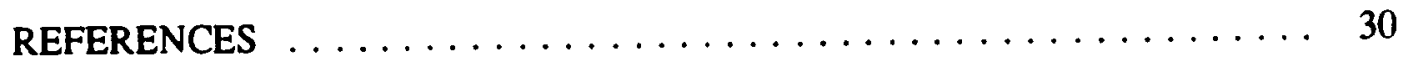


$-4$. 


\section{PREFACE}

Since 1986 the Geological Survey of Denmark (DGU) has been actively engaged in the development of image analysis programs for fibre characterization. The initiative was taken by Dr. Claus Henriksen (then Technical University of Denmark, presently Danish Technological Institute). Part of his Ph.D. study "Polymer composites for pumps" (1989) required precise knowledge of the spatial orientation of glass fibres in the polymer material. It soon became evident that electronic image analysis was a suitable method for undertaking the measurements. Development of the image analysis program was performed in close co-operation between Claus Henriksen and Torsten Hoelstad (DGU). The results are included in Claus Henriksens Ph.D. thesis (in Danish). As a result of the DGU effort on fibre orientation measurements, contacts were established to the Institute of Manufacturing Engineering, Technical University of Denmark regarding measurements of the length of dispersed fibres. A visit to the DGU Image Analysis Laboratory, June 1989 by M.Sc. Bent Schifter-Holm and M.Sc. Bent Hall Jensen initiated a nearly one year long phase of image analysis program development and comparison of the image analysis method with the conventional semi-manual method.

DGU is presently subcontractor for two programmes in the Centre for Polymer Composites under the "Materials Technology Development Programme" regarding routine measurements of fibre length and fibre orientation. The two programmes are "Designing and Processing of Injection Moulded Components" and "Ageing, Long Term Properties and Durability". The fibre length project is part of both programmes. It is with permission from those programmes that DGU publishes a part of the results.

Geological Survey of Denmark

December 1992

Torsten Hoelstad 


\begin{abstract}
A number of electronic image analysis techniques have been applied to preparations of glas fibres obtained from polymer based composites (PES and PPS matrix) in order to automate length measurements.

The image analysis sequence developed is described in detail. The functions of the sequence are based mainly on aspects of filtering in the spatial domain by means of convolution, mathematical morphology and conditional measuring. The key image analysis function is directional erosion. Using glycerol jelly strew preparations and transmitted light, the length of 500 glass fibres can be automatically measured in approximately 15 minutes with an array processor based image analysis system (IBAS 2). The image analysis method is tolerant of impurities and variations in fibre preparation density; the method produces consistent results and errors due to misinterpretation are negligible.
\end{abstract}




\section{INTRODUCTION}

Although measuring the length of well defined objects such as glass fibres is in essence a trivial problem, when considering large sample sizes (more than 500 fibres) and many preparations, the shortcomings of manual and semi-manual methods become evident. Measuring 500 fibres using the manual method takes 4-6 hours and involves many sources of error including photographic distortion, measuring with a ruler and operator fatigue (Sawyer 1979). Semi-manual methods using either an electronic measuring wheel or digitizer tablet reduces analysis time considerably (2000 fibres per hour, Obieglo and Roller 1985) but operator errors persist. The time needed for a semimanual analysis of 500 fibres on the projection and measuring wheel based equipment at the Institute of Manufacturing Engineering, Technical University of Denmark is about 30 minutes (Bent Hall Jensen pers. comm. 1990).

The problems of measuring fibre length automatically are mainly related to preparation quality. For preparations containing only discrete fibres, an automatic image analysis evaluation is easily done. The preparation approach was used by Sawyer (1979). He described a preparation method (reaction system) which effectively disperses glass fibres.

In the attempt to achieve a general automated length measuring method, the preparation approach is not practical because it is material specific, i.e. different preparation methods (reaction systems) are necessary for fibres made from different materials.

The KONTRON fibre length programme overcomes some of the preparation problems. The programme is capable of measuring crossing fibres, although this is only possible in preparations with very low fibre density (Fischer and Müller 1985).

The purposes of the fibre length measurement project reported here were to design and test an image analysis method which is (a) preparation tolerant (i.e. not overly dependent on fibre density and impurities), (b) fast, (c) involves no manual interaction and (d) produces consistent results.

Electronic image analysis, however, is not necessarily a method producing unambiguous results. The output from the image analyser is highly dependent on the design of the image analysis sequence. Therefore, it is extremely important to document preci- 
sely every step of the sequence. A substantial part of this report is devoted to this subject. The image analyser used is a Kontron/IBAS 2, but the fibre length measuring sequence proposed can easily be adopted to any array processor-based image analysis system working in the spatial domain.

\section{MATERIAL, PREPARATION AND OPTICAL SETUP}

The following two polymer based composite materials have been used, 1) Polyether Sulphone (PES), Victrex 4101 GL 30 from ICl, 30 weight \% fibre and 2) Polyphenylene Sulfide (PPS), Ryton R4 XT-HV from Phillips Petroleum Chemicals, 40 weight \% fibre. The polymer matrix has been bumed of with thermogravimetric analysis, temp. $20^{\circ} \mathrm{C} / \min$., max.temp. $650^{\circ} \mathrm{C}$.

The fibres can be mounted in various embedding media, but the best preparations were made with glycerol jelly; glycerol jelly preparations also have the advantage that they can be stored for decades (Poulsen, Gudmundsson, Hansen and Husfeldt 1990) and further investigations may be undertaken. The preparations were made on standard sized $(25 \times 75 \mathrm{~mm})$ microscope slides with $24 \times 40 \mathrm{~mm}$ cover slips. The fixed embedding medium and the preparation glass format facilitates sample handling.

The microscope used is a Zeiss Universal with a transmitted light setup. The objective is $x 2.5$, which gives a total magnification of $x 68$ on the image analyser screen. 


\section{ELECTRONIC IMAGE ANALYSIS}

The image analysis system adopted is the IBAS 2 (manufacturer Kontron Bildanalyse $\mathrm{GmbH})$. This is a two processor system with a conventional serial microcomputer as the host or control unit and an array processor as the image handling unit. The image handling unit consists of a $2 \mathrm{MB}$ video memory board (VMB), a memory address controller (MAC) and a microprogrammable array processor (MIAP).

The DGU image analysis configuration is shown on fig. 1 . The analogous signal generated in the TV-scanner (Bosch) mounted on the microscope is digitized in the ana$\log /$ digital (A/D) converter and stored in the VMB with a spatial solution of $512 \times 512$ pixels and a grey value solution of 8 bits ( 256 grey values). The stored images can be displayed on a conventional monitor via the D/A converter. The image manipulation is carried out by microprogram orders and microprogram sequences selected from the control computer. The programming is menu-oriented and is controlled via the keyboard and/or the digitizer tablet. The microscope is equipped with a motorized scanning table, a light intensity-based autofocus unit and a feedback light control unit.

The IBAS 2 image analysis system contains about 100 different image analysis functions. These functions are grouped in the following 11 groups: 1) image input functions, 2) functions to calibrate the system, 3) image enhancement functions, 4)interactive functions, 5) functions for creation of a binary (or a multiphase) image, 6) functions to influence binary or multiphase images, 7) functions to select measuring parameters, 8) evaluation functions, 9) functions for geometric and arithmetrical transformation of images, 10) general auxiliary functions and 12) functions for peripheral input/output operations. 


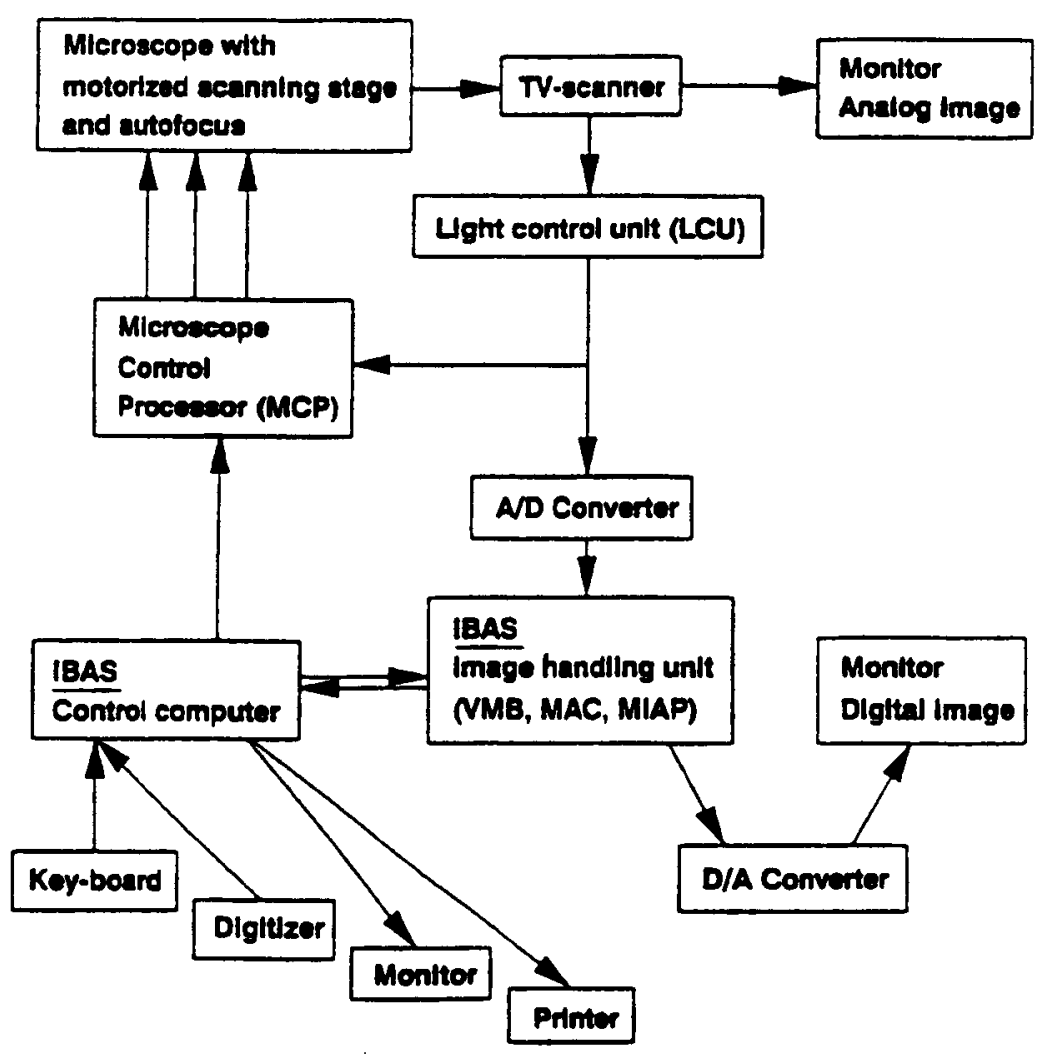

Fig. 1 Simplified block diagram of the image analysis system.

\section{CONSIDERATIONS ON THE DESIGN OF AN IMAGE ANALYSIS SEQUENCE}

Designing an image analysis measuring program can be a tedious task. Only very few general rules can be given, the rest is a question of trial and error. Critical aspects in image analysis of fibre preparations are: 1) a good optical set-up providing an optimal input image, 2) careful attention to magnification, illumination and focusing, 3) correction for uneven illumination, 4) avoidance of sensitive grey value thresholds and 5) recognition of fibres on well-defined criteria. 
One problem when using computer systems on images is the incompatibility with human vision. When solving an arithmetrical problem, the computer works in a way comparable to the human mind, i.e. computing the given expression sequentially and producing the predicted answer. For images, however, human perception and computer (non-neural network system) perception are completely different. Besides such characteristics of the human visual system as brightness adaptation and the Mach-band-effect (Gonzalez \& Wintz, 1977), the major difference is that human perception is biased by past experience. Thus one subconsciously interprets and instantly determines the object in fig. 2 to be three fibres, whereas the image analysis system would identify only a single object.
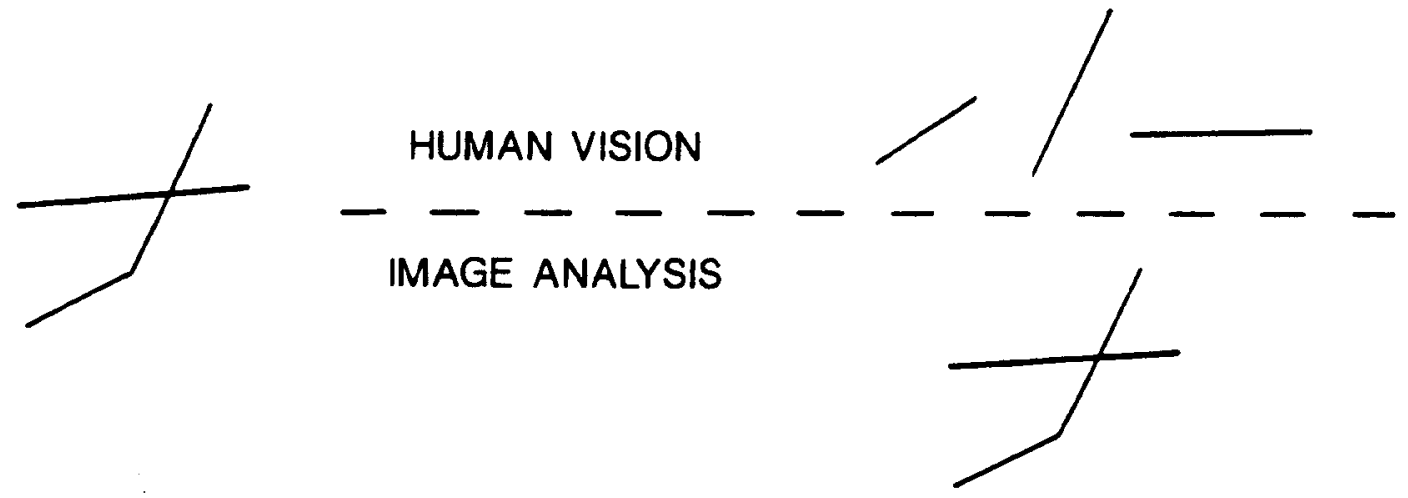

Fig. 2 Example of the difference between human visual perception and that of image analysis.

The consequence of these differences in visual perception is that the effect of the various image enhancement functions on the quality of fibre discrimination is difficult to predict and, therefore, a strong element of time-consuming trial and error is necessary in the design phase. It is important, therefore, to test a given image analysis sequence on several fields of view. The selection of the most suitable treatment can only be done subjectively, based on visual comparison of images. Comparison of images is, however, facilitated by image analysis functions such as overlays, arithmetrical and logical combination of images and grey value histograms. 


\section{THE IMAGE ANALYSIS SEQUENCE}

The fibre length image analysis sequence can be subdivided into 9 main groups, these are:

1) Shade correction reference image

2) Measuring frame extension

3) Clearing of image memories

4) System calibration

5) Image input and enhancement

6) Directional erosion

7) Conditional measuring

8) Length measurement and data storage

9) Special features

A print-out of the entire image analysis program is shown on fig. 3. Owing to machine-specific limitations regarding program length, the image analysis sequence is divided into two programs. Program 012 (fig. 3A) includes items 1-3 and program 098 (figs. 3B-3E) items 4-9. 


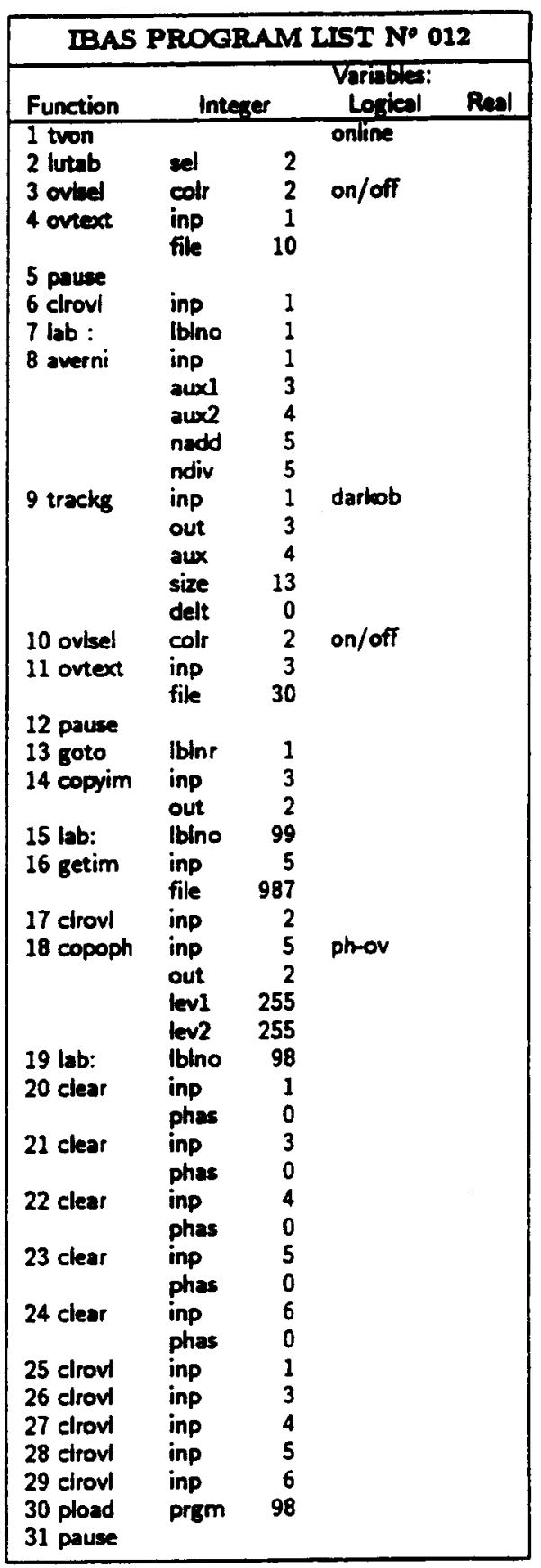

Fig. 3A. The image analysis program. Prgm.012, steps 1-31. Shade correction reference image (steps 1-15), measuring frame extension (steps 16-19) and clearing of image memories (steps 20-31). 


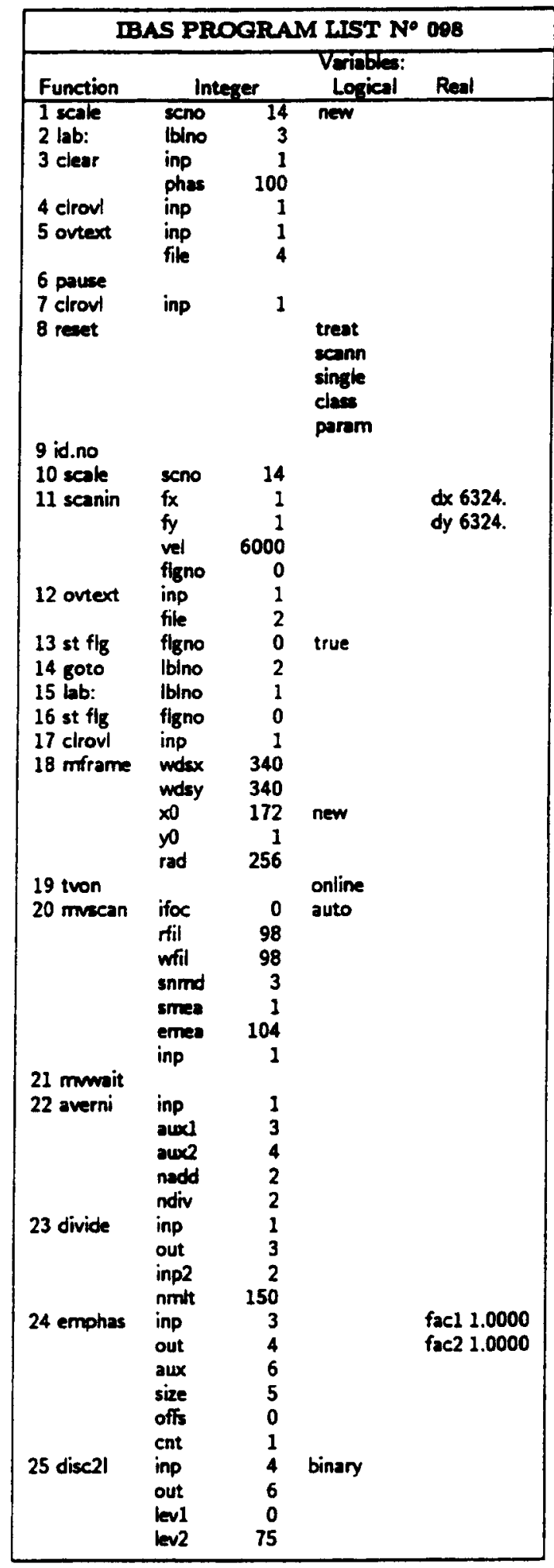

Fig. 3B. The image analysis program. Prgm.098, steps 1-25. System calibration (steps 1-18) and image input and enhancement (steps 15-25). 


\begin{tabular}{|c|c|c|c|c|}
\hline \multicolumn{5}{|c|}{ BBAS PROGRAM IIST N'098 } \\
\hline \multirow{2}{*}{$\begin{array}{l}\text { Function } \\
26 \text { st fig } \\
27 \text { open }\end{array}$} & \multicolumn{2}{|c|}{ Interer } & $\begin{array}{l}\text { Veriables: } \\
\text { Lorical }\end{array}$ & Real \\
\hline & $\begin{array}{l}\text { theno } \\
\text { inp }\end{array}$ & $\begin{array}{r}55 \\
6\end{array}$ & & \\
\hline & out & 5 & & \\
\hline & phas & $\begin{array}{r}255 \\
2\end{array}$ & & \\
\hline & mode & 1 & & \\
\hline \multirow[t]{5}{*}{28 dilate } & inp & 5 & & \\
\hline & out & 4 & & \\
\hline & phas & 255 & & \\
\hline & cnt & 1 & & \\
\hline & mode & 5 & & \\
\hline \multirow[t]{2}{*}{29 boolop } & inp & $\begin{array}{l}4 \\
5\end{array}$ & and & \\
\hline & inp2 & 6 & & \\
\hline \multirow[t]{2}{*}{30 copoph } & inp & 2 & & \\
\hline & out & 5 & ouph & \\
\hline \multirow{3}{*}{$\begin{array}{l}31 \text { disply } \\
32 \text { ident }\end{array}$} & inp & 5 & & \\
\hline & inp & 5 & 8-conn & \\
\hline & $\begin{array}{l}\text { out } \\
\text { marg }\end{array}$ & $\begin{array}{l}3 \\
2\end{array}$ & & \\
\hline \multirow{4}{*}{$\begin{array}{l}33 \text { upn } \\
34 \text { user }\end{array}$} & nupn & 999 & & \\
\hline & $\begin{array}{l}\text { nuse } \\
\text { nets }\end{array}$ & 10 & obj & $\begin{array}{l}\text { low } 0.000 \\
\text { high .200 }\end{array}$ \\
\hline & $\operatorname{modx}$ & 1 & & \\
\hline & mody & 1 & class & \\
\hline \multirow[t]{3}{*}{35 user } & $\begin{array}{l}\text { nuse } \\
\text { nets }\end{array}$ & $\begin{array}{r}2 \\
10\end{array}$ & obj & $\begin{array}{l}\text { low } 9.000 \\
\text { high } 15.42\end{array}$ \\
\hline & $\operatorname{modx}$ & 1 & & \\
\hline & mody & 1 & class & \\
\hline \multirow[t]{3}{*}{36 weer } & nuse & 3 & & low 2.747 \\
\hline & ncts & $\begin{array}{r}10 \\
1\end{array}$ & abj & high 10000. \\
\hline & mody & $i$ & class & \\
\hline \multirow[t]{2}{*}{$37 d \max$} & $\begin{array}{l}\text { ncls } \\
\text { modx }\end{array}$ & $\begin{array}{r}10 \\
1\end{array}$ & single & $\begin{array}{l}\text { low } 96.38 \\
\text { high } .1000 E+06\end{array}$ \\
\hline & mody & 1 & & \\
\hline \multirow[t]{2}{*}{$38 \mathrm{dmin}$} & nets & 10 & & low 0.000 \\
\hline & $\begin{array}{l}\operatorname{modx} \\
\operatorname{mody}\end{array}$ & $\begin{array}{l}1 \\
1\end{array}$ & & high 54.15 \\
\hline \multirow[t]{3}{*}{$39 \mathrm{~ms} / \mathrm{skp}$} & inp & 3 & skip & \\
\hline & out & 5 & & \\
\hline & gorf & 1 & obj & \\
\hline \multirow[t]{3}{*}{40 measur } & inp & $\begin{array}{l}5 \\
1\end{array}$ & & \\
\hline & chan & 1 & obj & \\
\hline & space & 1 & & \\
\hline \multirow{5}{*}{$\begin{array}{l}41 \text { if } 1 / g \\
42 \text { contur }\end{array}$} & fligno & 55 & & \\
\hline & inp & 5 & & \\
\hline & $\begin{array}{l}\text { out } \\
\text { phas: }\end{array}$ & $\begin{array}{l}1 \\
0\end{array}$ & & \\
\hline & pheo & 251 & & \\
\hline & mode & 7 & & \\
\hline
\end{tabular}

Fig. 3C. The image analysis program. Prgm.098, steps 26-42. Horizontal erosion (steps 26-31), conditional measuring (steps 32-39) and measuring (step 40). 
Fig. 3D. The image analysis program.

Prgm.098, steps 43-62.

Vertical erosion (steps 44-46),

$45^{\circ}$ erosion (steps 54-56),

conditional measuring

(steps 43, 48-49 and 53, 58-59)

and measuring (step 50 and step 60).
IBAS PROGRAM LIST N' 098

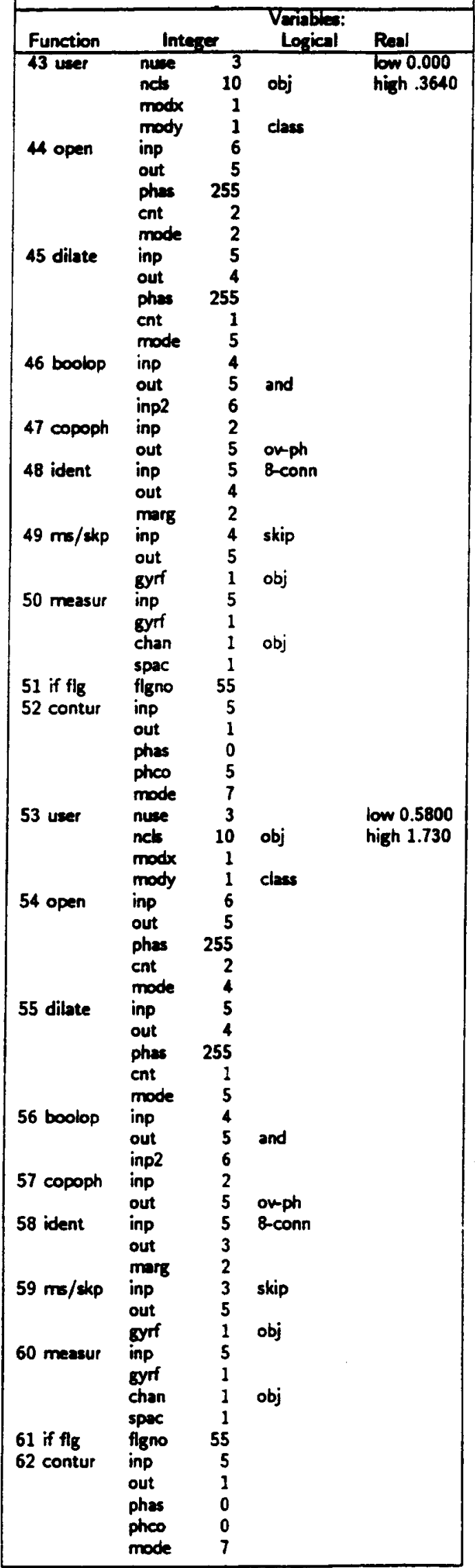




\begin{tabular}{|c|c|c|c|c|}
\hline \multicolumn{5}{|c|}{ BBAS PROGRAM IIST N' 008} \\
\hline \multirow{2}{*}{$\frac{\text { Function }}{63 \text { open }}$} & \multicolumn{2}{|c|}{ Integer } & $\begin{array}{l}\text { Veriasie: } \\
\text { Lorical }\end{array}$ & Real \\
\hline & & 6 & & \\
\hline & out & $\begin{array}{r}5 \\
255\end{array}$ & & \\
\hline & ent & 2 & & \\
\hline & mode & 3 & & \\
\hline \multirow[t]{4}{*}{64 dilate } & inp & 5 & & \\
\hline & & 4 & & \\
\hline & phas & 255 & & \\
\hline & cnt & $\begin{array}{l}1 \\
5\end{array}$ & & \\
\hline \multirow{3}{*}{65 boolop } & inp & 4 & & \\
\hline & out & 5 & and & \\
\hline & inp2 & 6 & & \\
\hline \multirow[t]{3}{*}{66 ident } & inp & 5 & B-conn & \\
\hline & out & 3 & & \\
\hline & marg & 2 & & \\
\hline \multirow[t]{3}{*}{$67 \mathrm{~ms} / \mathrm{skp}$} & inp & 3 & skip & \\
\hline & out & 5 & & \\
\hline & syr & 1 & obj & \\
\hline \multirow[t]{4}{*}{68 measur } & inp & 5 & & \\
\hline & Byrf & 1 & & \\
\hline & chan & 1 & obj & \\
\hline & spac & 1 & & \\
\hline \multirow{5}{*}{$\begin{array}{l}69 \text { if flg } \\
70 \text { contur }\end{array}$} & flgno & 55 & & \\
\hline & inp & 5 & & \\
\hline & out & $\begin{array}{l}1 \\
0\end{array}$ & & \\
\hline & $\begin{array}{l}\text { phis } \\
\text { pheo }\end{array}$ & 255 & & \\
\hline & mode & 7 & & \\
\hline 71 disply & inp & 1 & & \\
\hline 72 lutab & sel & 3 & & \\
\hline 73 if $\mathrm{flg}_{\mathrm{g}}$ & flgno & 55 & & \\
\hline 74 wait & misec & 2000 & beep & \\
\hline \multirow{6}{*}{$\begin{array}{l}75 \text { lab: } \\
76 \text { if flg } \\
77 \text { pause } \\
78 \text { loop }\end{array}$} & $\begin{array}{l}\text { freq } \\
\text { Iblno }\end{array}$ & $\begin{array}{r}500 \\
2\end{array}$ & & \\
\hline & figno & 0 & & \\
\hline & & & & \\
\hline & Ibino & 1 & & \\
\hline & Ient & 1 & & \\
\hline & entno & 15 & & \\
\hline \multirow{4}{*}{$\begin{array}{l}79 \text { clear } \\
80 \text { ovtext }\end{array}$} & inp & 5 & & \\
\hline & phase & 100 & & \\
\hline & inp & 5 & & \\
\hline & & 0 & & \\
\hline \multirow{8}{*}{$\begin{array}{l}81 \text { pause } \\
82 \text { outegl } \\
83 \text { pause } \\
84 \text { mucan }\end{array}$} & & & store & \\
\hline & & & . & \\
\hline & ifoc & 0 & auto & \\
\hline & ril & 12 & & \\
\hline & wril & 12 & & \\
\hline & sind & 1 & & \\
\hline & $\begin{array}{l}\text { Smes } \\
\text { emea }\end{array}$ & $10 \overline{4}$ & & \\
\hline & inp & 1 & & \\
\hline \multirow{4}{*}{$\begin{array}{l}85 \text { muwait } \\
86 \text { clrovi } \\
87 \text { clear }\end{array}$} & & & & \\
\hline & inp & 5 & & \\
\hline & inp & 1 & & \\
\hline & phas & 100 & & \\
\hline 88 goto & Iblno & 3 & & \\
\hline
\end{tabular}

Fig. 3E. The image analysis program. Prgm.098, steps 63-89. $135^{\circ}$ erosion (steps 63-65), conditional measuring (steps 66-67), measurement (step 68) and data storage (step 82). 


\section{Shade correction reference image}

prgm.012, steps $1-15$

Microscopes in general do not produce evenly illuminated fields of view, so that an electronic illumination correction (shading) is necessary. A prerequisite for this correction is knowledge of the grey value distribution of the entire background. A simple way of obtaining that information is to record an empty field of view. It is important, however, that the empty field of view is recorded at the same focal level as the fibres. This means that the empty field of view must originate from an actual fibre preparation. Since fibre preparations seldom contain completely empty areas, it is necessary to electronically remove impurities and/or small fibres. This is done by applying an electronic filter (step 9 - TRACKG). A $13 \times 13$ pixels matrix is tested for every position in the image and the grey value of the central pixel is replaced by the maximum grey value within the matrix. The result is a homogeneous image which represents the background grey level distribution. This image is stored in image memory no. 2 for later use (step 14 - STORIM).

\section{Measuring frame extension}

Prgm.012, steps 16-19.

In order to avoid biased sampling due to edge effects when measuring successive and aligned fields of measurement, a measuring frame must be introduced. The IBAS system, however, includes only two types of measuring frames, a circular and a quadrangular. This is inadequate when measuring fibre length, and it is necessary to extend the righthand side of the quadrangle downwards (for further explanation see p.22 and Gundersen 1981). The measuring frame extension which is stored on floppy disc is loaded (step 16 - GETIM) and stored in the overlay of image memory 2 (step 18 - COPOPH).

\section{Clearing of image memories}

Prgm.012, steps 20-31.

Clearing all available image memories and corresponding overlays except for image memory 2, which contains the background reference image and the measuring frame extension. Program 98 is loaded (step 30 - PLOAD). 


\section{System calibration}

Prgm. 98, steps 1-14.

Before an analysis is initiated the system must be calibrated. This includes adjusting the microscope and light source to the optimal level according to manufacturers' instructions. The appropriate micrometer to pixel conversion factor is selected (step 1 SCALE). This conversion factor is, of course, dependent on the selected magnification. The micrometer to pixel conversion factor is at the chosen magnification 4.65 corresponding to a total screen dimension of 2380 microns. This is a sensible magnification because it results in an adequate resolution for the smallest fibres (100 microns equals approximately 22 pixels) and accommodates the longest fibres ( 800 microns equals approximately a third of the screen). The scanning table is moved manually to the upper right corner of the cover slip (step 3 - OVTEXT) (the position of origin $0,0, z$ ). The position is selected with due consideration to the scope of the subsequent automatic run i.e. all fields of view should be within the area of the cover glass. The various buffers are cleared (step 8 - RESET). The data buffer is then labelled (step 9 ID.NO) unambiguously, typically using the date and sample number. The scanning table is then initialized (step 11 - SCANIN).

\section{Image input and enhancement}

prgm.098, steps $15-25$

After the system calibration routine, the number of fields of view to be analysed and measured is set. The parameter CNT of the loop (step 15 - LAB: and step 78 LOOP) is set to the desired fields of view. In the present investigation 10-30 fields of view out of a maximum of $\mathbf{4 4}$ have been analysed in order to obtain a minimum count of 500 fibres. The maximum number of loops is determined by the number of steps in the subprogram which runs the automatic scanning stage. The number of steps can easily be increased. The measuring frame is loaded (step 18 - MFRAME). The measuring frame covers an area of approx. $1,6 \times 1,6 \mathrm{~mm}$ in the upper right portion of the screen. The TV-scanner is switched directly to the colour monitor (step 19 - TVON). The scanning stage is moved to the first set of coordinates defined in the coordinate file RFIL (step 20 - MVSCAN). The coordinate file consists of $4 \times 11$ fields of view 
which do not overlap or have gaps between them. As the movement of the scanning stage is performed in parallel with the measuring program, evaluation by the measuring program might take place while the scanning stage is still moving. The program thus waits until the scanning stage is stopped (step 21 - MVWAIT). Two images of the actual field of view are digitized and stored and the average image is computed (step. 22 - AVERNI). This is done to reduce the effects of TV-scanner artefacts (noise). The shade correction (correction for uneven illumination) involves dividing the original image by the background reference image and multiplying by a constant (150) (step 23 - DIVIDE). The constant is selected with due consideration to optimal grey value
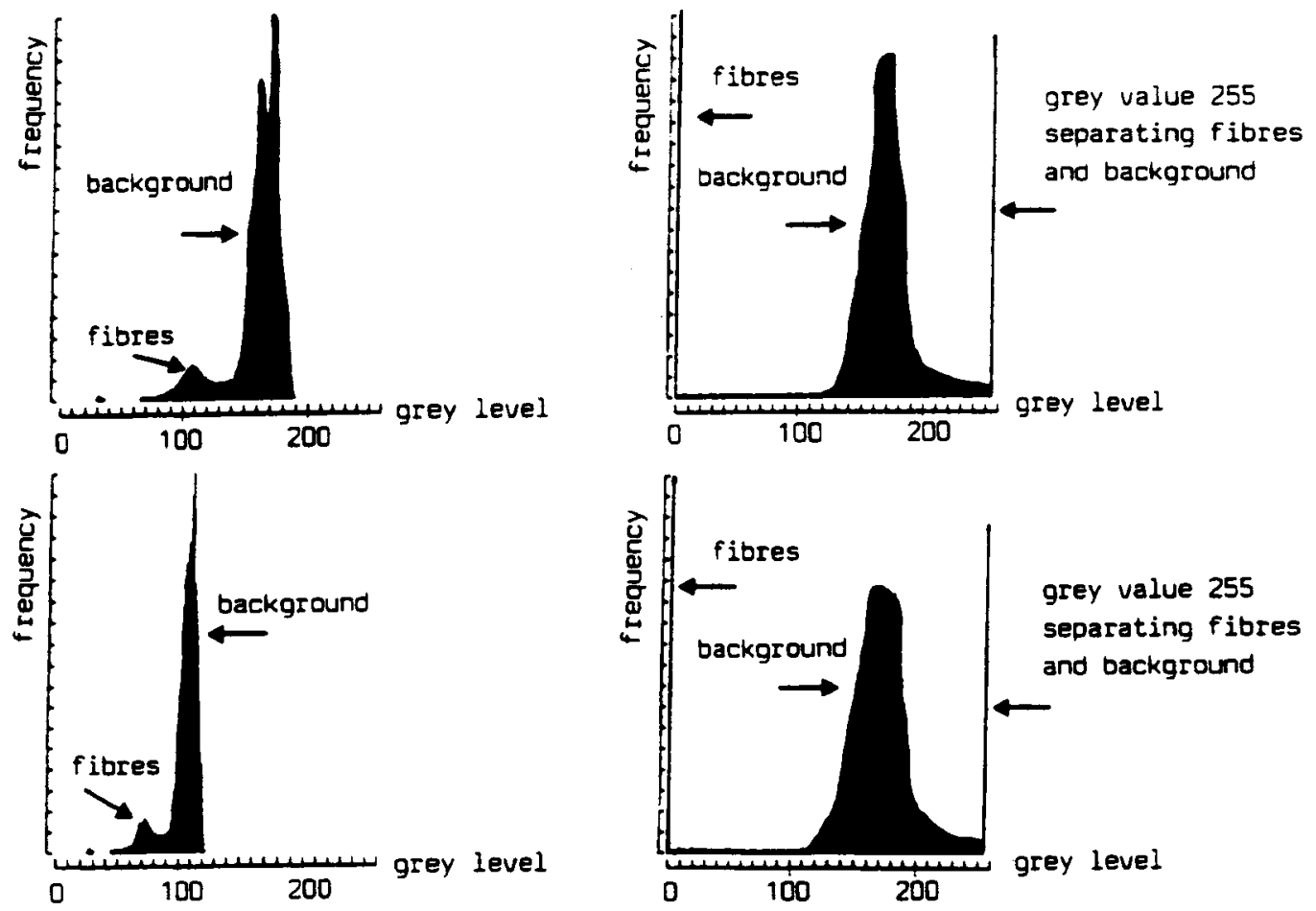

Fig. 4. Grey value distributions showing the effect of image enhancement. The two distributions to the left represent the untreated input image at different light intensities. The distributions to the right show the result after shade correction and contour enhancement. 
distribution in the resulting shade-corrected image. The shade-corrected image thus contains background grey values around 150 and corrected fibre grey values. The shade-corrected image is then treated with an effective contour enhancement filter (step 24 - EMPHAS). Computing the difference between the original image (the shadecorrected image) and the result of a $5 \times 5$ matrix lowpass (average) filtering gives a highpass filtered image. By adding this highpass filtered image to the original image, contour enhancement is achieved, i.e. the slope of the transition between the background and the fibres gets steeper. The grey value distribution of the image subjected to both shade correction and contour enhancement is nearly independent of the initial illumination (fig. 4). This facilitates setting of absolute grey value thresholds (step 25 DISL2L) for creation of the binary image. As the vast majority of fibres have a grey value of 0 and the background value is above 120 (fig. 4) a safe discrimination interval certainly is 0.75 . Furthermore, the fibres in most cases are separated from the background by a grey value of 255 (fig. 4).

\section{Directional erosion}

Prgm.098, steps 26-31, 44-46, 54-56 and 63-65

This is the key feature of the present fibre length measurement image analysis sequence. The original binary image is opened (eroded and dilated) by four different structuring elements (step 27, 44, 54, 63 - OPEN). The structuring elements used are vectors of three pixels and with the following directions: horizontal, vertical, diagonal $45^{\circ}$ and diagonal $135^{\circ}$ ). By eroding twice with for example a horizontal vector, all image features (fibres) containing less than 4 horizontal pixels are deleted. In this way crossing fibres are eliminated. However, the ends of the remaining fibres are also affected and, therefore, an additional dilation is executed (step 28, 45, 55, 64 - DLATE). The structuring element used is a $3 \times 3$ pixels cross, which results in a general expansion of the remaining fibres. By combining this image with the original binary image (step 29, 45, 56, 65 - BOOLOP) the exact fibre length and shape is restored. The directional erosion procedure is illustrated on fig. 5 . 


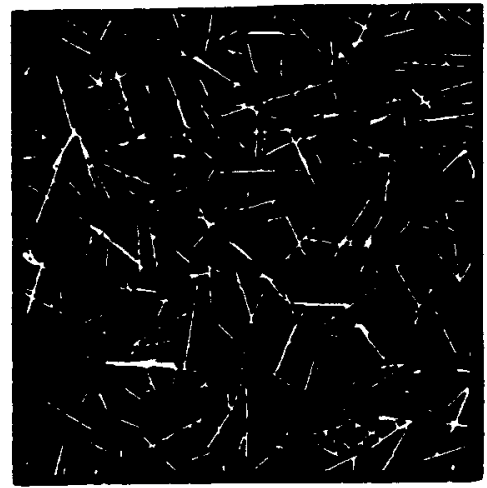

A. The original binary image

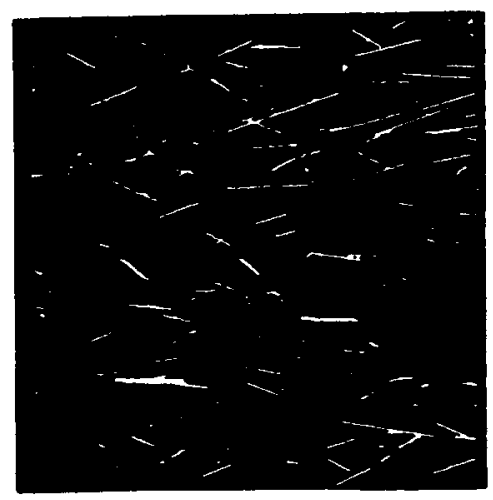

C. Image after $B$ is dilated and combined with $A$

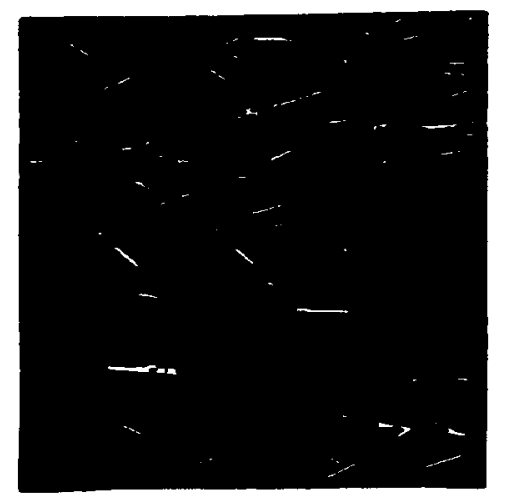

B. Image eroded with horizontal structuring element

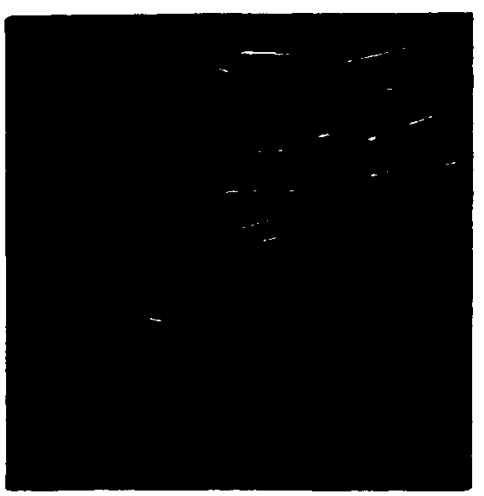

D. Recognized "horizontal"

fibres i.e. image $\mathbf{C}$ subjected to conditional measuring

Fig. 5 The main steps of the image analysis sequence (horizontal case). Only part of the fibres are shown in $\mathrm{D}$ due to use of measuring frame.

\section{Conditional measuring}

Prgm.098, steps 32-39, 43, 48-49, 53, 58-59 and 66-67

Before testing for specific features, it is necessary that each of the image objects is read by the image analyser as individuals and different from the other image objects, i.e. are identified (step 32, 48, 58, 66 - IDENT). This involves the use of a connectivity rule, which states that all object pixels are connected in eight directions, whereas the background pixels are connected in four directions only. In this way the individual objects are identified, which in practice means that they are given separate grey values. The method used in this image analysis program for selecting fibres with predefined 
properties (i.e. single straight fibres) is the measure/skip routine. It consists of 3 steps. These are identification of objects in the binary image, setting parameter thresholds and the actual conditional measuring. The result of the measure/skip routine is that only those fibres which fulfil the conditions set by the parameter thresholds are left in the image. These fibres are still identified, so that the length measurement can follow immediately. The selection criteria are explained under the paragraph on parameter thresholds. The user-defined parameters (steps 34-36, 43, 53 - USER) are calculated in the subprogram UPN. This subprogram is loaded within the image analysis program (step 33 - UPN) and is called by the parameter USER. The result of the conditional measuring for one field of view and the horizontal direction is shown on fig. 5D.

\section{Length measurement and data storage}

prgm.098 steps $40,50,60,68,82$ and 84 .

The actual length measurement is done separately for each direction on the identified images (steps 40, 50, 60 and 68 -MEASUR). Definition of the length parameter (DMAX) is given under the paragraph on sources of error. All measurements are stored in a data buffer and are transferred to floppy disc (step 89 - OUTSGL) when the analysis is completed. The scanning table is repositioned (step 84 - MVSCAN) and a new analysis can be initiated.

\section{Special features}

Prgm.012 and prgm.098

The programs are equipped with the necessary user interface facilities in the form of explanatory overlay texts (prgm. 012, step 4 and 11; prgm.098 steps 5, 12 and 80 OVTEXT). Thus operators with little or no prior knowledge of image analysis can be trained to run the programs in the course of a few hours. For demonstration and testing purposes a display facility can be selected (prgm.098, step 26 - ST FLG, steps 41, 51, 61, 69 and 73 - IF FLG, steps 42, 52,62 and 70 - CONTUR, step 71 - DISPLY, step 72 - LUTAB and step 74 - WATT). The program waits and highlights the fibres selected for length measurement. Each of the four directions are shown in different colours. 


\section{MEASURDNG PROCEDURE}

Depending on the fibre density in the preparations, 10 to more than 30 fields of view have been analysed in order to obtain a minimum count of 500 fibres.

A measuring frame was used to avoid biased sampling due to edge effects,. The measuring frame occupies an area of $340 \times 340$ pixels and is displaced in the total visible field to the upper right leaving a margin, 172 pixels wide, along the lower and the left side. Fibres touching the left or the lower side of the measuring frame therefore can have a dimension of 172 pixels ( 800 micron given a scale of 4.65 micron/pixel) and yet be included fully in the total visible field. When measuring a field of view, those fibres that lie outside the measuring frame or are cut by the upper or right hand side of the measuring frame are not taken into account. Thus, when measuring successive and aligned measuring frames, the greater probability of longer fibres being sampled is corrected for. In addition, the probability of recording fibres truncated by the edge of the total visible field is greatly reduced.

\section{PARAMETER THRESHOLDS}

Following directional erosion the image contains a number of undesirable image elements (fig. $5 \mathrm{C}$ and fig. 6). These image elements are removed by conditional measuring. The selection criteria are size, shape and orientation:

Size: $\quad$ DMIN $=$ Minimum diameter

DMAX = Maximum diameter

LONGAREA $=$ AREA/DMAX $=$ DMIN computed

Shape: $\quad$ LONGFORM $=$ DMIN/DMAX

Orientation: $\quad$ ORIENT $=$ FERETX/FERETY $=$ COTANGENS $\alpha$

Where: FERETX = projection in $\mathrm{x}$-direction

FERETY $=$ projection in $y$-direction

$\alpha=$ angle between $x$-axis and fibre 


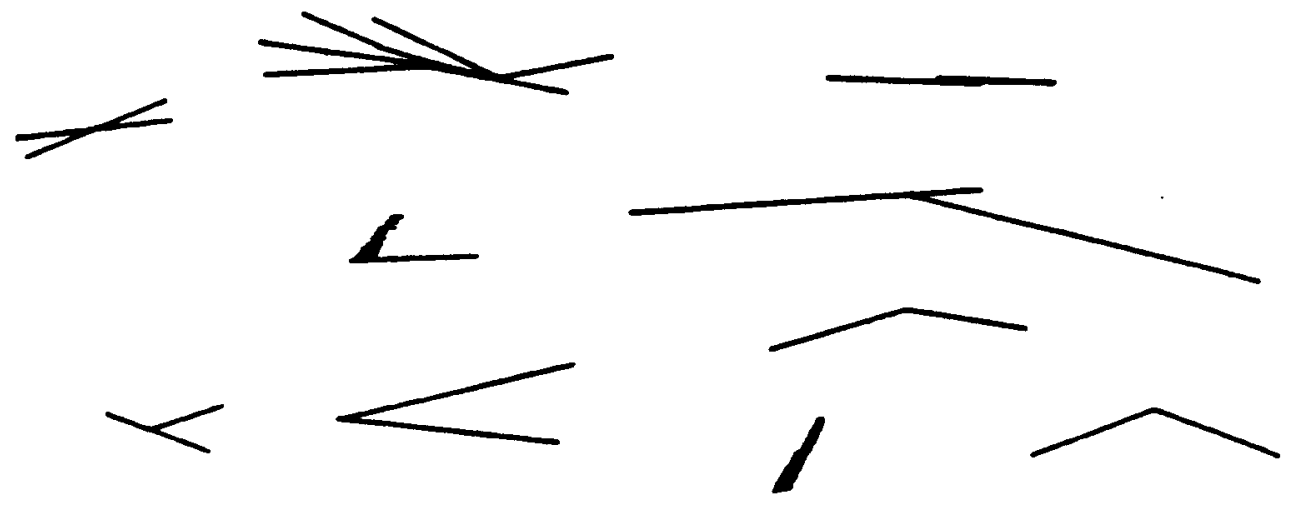

Fig. 6. Examples of undesirable image elements, i.e. agglutinates, overlapping fibres and fibres touching at an angle to each other.

Initially, the thresholds of the LONGAREA parameter must be determined for the actual fibre type. The distribution of LONGAREA based on measurements of 500 randomly selected fibres is shown on fig. 7. The upper threshold of LONGAREA is selected as the mean plus 2 standard deviations and the lower threshold as the nearest integer below the measured values. Thus, the thresholds of LONGAREA for the present fibre type are 15.42 and 9.0 microns.

ABS. FREQUENCY

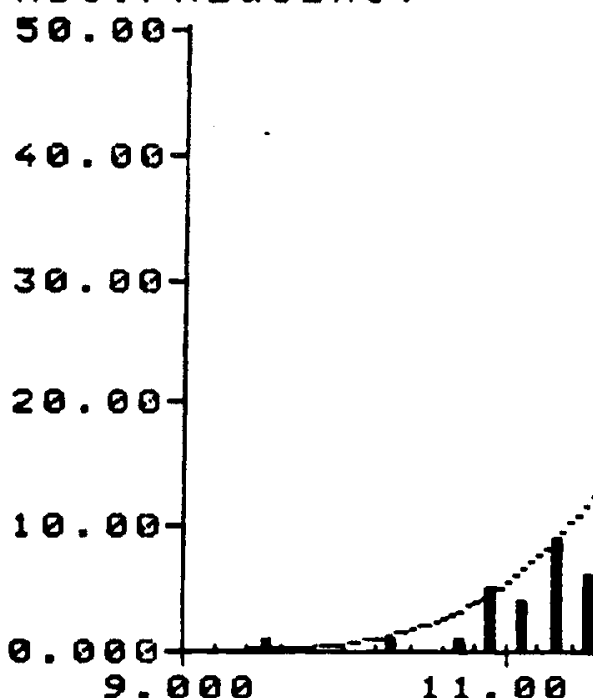

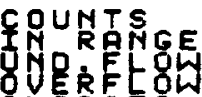

CLESSES

INTERUALOQ000 PIITIMịm 00000

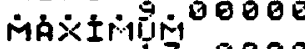
MÉं $ं .17 .0000$

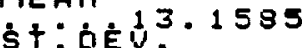
MI

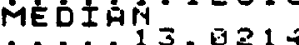
Ḿó丶 microns

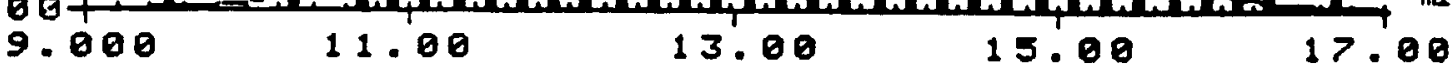

LONGAREA

Fig. 7. Distribution of parameter LONGAREA. 
A lower threshold for DMAX is introduced to ensure that the shortest fibres are represented by a minimum of 18-22 pixels. The threshold is defined as the upper threshold of LONGAREA $\times \mathrm{A}$, where $\mathrm{A}$ is selected so that the result of the expression: (upper threshold of LONGAREA $\times$ A / scalefactor) lies within the interval 18-22. The lower threshold of DMAX (96.38 microns) is thus $R$ (6.25) times larger than the upper threshold of LONGAREA (15.42 microns) and is represented by a minimum of 18-22 pixels (20.73).

The upper threshold of DMIN is given by the expression: $(340 \times$ scalefactor $x$ sin $1.41^{\circ}+$ upper threshold of LONGAREA). The longest fibre that can be handled given the chosen magnification is defined as equal to the size of the measuring frame, which in the present investigation is 340 pixels or ( $340 \times$ scalefactor) microns. Since DMIN is measured as the shortest of 32 projections, DMIN will in the extreme case be overestimated by a factor of $\sin 90^{\circ} / 32=\sin 1.41^{\circ}=0.0245$. Adding this correction (340 $\times$ scalefactor $\times 0.0245)$ to the upper threshold of LONGAREA (the maximum computed DMIN) gives the best estimate for the upper threshold of DMIN.

The upper threshold of LONGFORM (DMIN/DMAX) is defined empirically as 0.2 . thus the length (DMAX) must be at least 5 times the diameter (DMIN).

The thresholds in the present investigation are :

LONGAREA: 9.0 - 15.42 microns

LONGFORM: $0-0.2$

DMAX : $96.38-100,000$ microns

DMIN : 0 - 54.15 microns

These parameter thresholds effectively remove such features as overlapping fibres, agglutinates, fibres touching at an angle to each other and impurities (fig. $5 \mathrm{C}$ and 6). The resultant image exhibits only image elements fulfilling these threshold criteria, i.e. discrete fibres. 
However, a problem arises when fibres are oriented in such a way that they are detected by two directions of the erosion and, therefore, are measured twice. This problem is overcome by setting thresholds for the parameter ORIENT.

ORIENT $=$ FERETX/FERETY $=$ cotangens $\alpha$, where $\alpha=$ angle between $x$-axis and fibre.

The thresholds are:

Vertical erosional vector: $\cot 90^{\circ}-\cot 70^{\circ}=0-0.364$

$45^{\circ}$ erosional vector: $\cot 60^{\circ}-\cot 30^{\circ}=0.50-1.73$

$135^{\circ}$ erosional vector: $\cot 60^{\circ}-\cot 30^{\circ}=0.50-1.73$

Horizontal erosional vector: $\cot 20^{\circ}-\cot 0^{\circ}=2.74-10,000$

\section{SAMPLING}

In order to obtain statistically correct measurements, it is essential that sampling is random. Given random dispersion of fibres in the preparations, bias might be introduced by the conditional measurement. However, within given size ranges, the parameters used are exclusively shape-dependant and therefore straight fibres are selected regardless of their length. This can be illustrated by comparing the result of manual measurement of all fibres with the result of measurement based on sampling by the automatic method. The mean values (90\% probability intervals) were $205.4+/-7.4$ microns and $202.3+/-5.28$ microns respectively, i.e. no significant differences are noted.

\section{FIBRE AND PREPARATION REQUIREMENTS}

Given the principle behind the directional erosion, it is clear that only straight (and weakly curved) fibres can be measured. Furthermore, the fibres must exhibit reasonable contrast and they must have clean surfaces. The preparations must be free of objects containing straight segments (hair, wool fibres etc.) whereas all other objects such as 
bubbles are of no conseqence. The fibres for the preparations must be randomly sampled from the total population of fibres.

The fibre density in the preparations has been recorded for three different preparations. Densities ranging from 8.5 to 50.4 fibres/ square micron are accepted without problems. The percentage of fibres extracted for measurement naturally decreases with increasing density, although as much as $57 \%$ were extracted from the high density preparation compared to $70 \%$ from the low density preparation. The total number of fibres extracted for measurement increased by a factor of five from the low density to the high density preparation and the measurement time decreased from 2.4 to 1.1 sec./fibre.

\section{SOURCES OF ERROR}

Three types of errors can be identified. These are errors related to the actual image analysis functions, to the length measurement method and to misidentification.

Examples of errors which typically will affect the geometry of the fibres are those introduced by the various electronic filters, the segmentation, the directional erosion and noise. The sum of these errors will cause differences between identical runs of the same sample. The order of magnitude of these differences is less than $0.31 \%$ based on two tests of two runs covering the same 20 fields of view.

The fibre length (DMAX) is obtained from the longest of 32 projections. Because of the limited number of projections, the length will be inaccurately determined in all cases except for the case where the projection plane and the fibre are perfectly aligned. The error can be expressed as:

(DIAM $\sin \alpha 1$ - (DMAX - DMAX $\cos \alpha 1)$ )

where DIAM is the fibre diameter and $\alpha 1$ is the deviation from the perfect projection. With the exception of the unlikely cases where fibres are extremely thin and very long, the error will cause an overestimation of the fibre length. Given maximum deviation from the perfect projection, $\alpha 1=90^{\circ} / 32 / 2=1.4063^{\circ}$ and a maximum DMIN/DMAX ratio of 0.2 , the result is a maximum overestimate of $0.46 \%$. 
The number of cases of misidentification have been recorded for six samples. The relative frequency of misidentification ranges from $1.35 \%$ to $2.28 \%$ with an average of $1.67 \%$ - or 54 misidentifications out of a total of 3202 identifications. The six samples tested also contained six non-glassfibre particles misidentified as fibres, thus increasing the total error to $1.87 \%$. The most common errors are fibres touching each other at a wide angle or fibres overlapping slightly. Thus misidentification will most likely will result in an overestimation of the length. The order of magnitude of this overestimation is $1.2 \%$ for the mean value based on a measurement of a sample with $2 \%$ misidentifications.

\section{CONCLUSIONS}

The image analysis programme developed utilizes the fact that in order to obtain statistically correct measurements, only a part of the fibres within a field of view need to be measured, given that the selection is done randomly. By applying this approach, preparations problems are largely overcome, and, kept within reasonable limits, the density of fibres in preparations is no longer a critical factor.

The principle behind the method is directional erosion i.e. removal of fibres oriented obliquely to the measuring direction. The directional erosion is performed in four directions. In combination with conditional measuring, it is possible to extract $40-70 \%$ of the fibres in the field of view. The main parameter in relation to the conditional measurement is the calculated fibre diameter.

The image analysis fibre length measurements are consistent and misinterpretation accounts, on average, for less than $2 \%$ of the measurements. 


\section{ACKNOWLEDGEMENTS}

Bent Hall Jensen (Danfoss $\mathrm{a} / \mathrm{s}$ ) and Claus Henriksen (Danish Technological Institute) are thanked for constructive co-operation, support and criticism. Thanks to Heinke Andersen (DGU) and Hanne Danielsen (DGU), who swiftly and accurately typed the manuscript and to Jon Ineson (DGU) who carefully corrected the English. Stefan Hultberg (DGU) is thanked for reading and approving the final manuscript at short notice.

\section{REFERENCES}

Fischer, G. \& Müller, U., 1985: Einsatz der Bildanalyse bei der Qualitätssicherung in der Kunststoffindustrie. QZ Qualitätstechnik, (6), 164-168.

Gonzalez, R. C. \& Wintz, P., 1977: Digital Image Processing. Addison-Wesley Publ. Comp., London, 431 pp.

Gundersen, H.J.G., 1981: Stereologi. Eller hvordan tal for rumlig form og indhold opnås ved iagttagelse at strukturer på snitplaner. Lægeforeningens Forlag, Kbh., 25 pp.

Obieglo, G. \& Roller, B., 1985: Computerunterstütztes System zur Längenmessung von Glasfasern aus glasfasergefüllten thermoplastischen Kunststoffen. Kunststofberater (5), 29-31.

Poulsen, N.P., Gudmundsson, L., Hansen, J.M. \& Husfeldt, Y., 1990: Palynological preparation techniques, a new Macerationtank-method and other modifications. DGU series C. no. 10, 1-23.

Sawyer, L.C., 1979: Determination of fibreglass Length: Sample Preparation and Automatic Image Analysis. Polymer engineering and science, 19/ 5, 377-382. 
A robust and fully automated method is presented for measuring the length of dispersed straight fibres.

The method deals effectively with the problem of crossing fibres and it is tolerant of impurities and variations in fibre preparation density. 